\title{
ATTITUDE OF ANTENATAL MOTHERS TOWARDS CAESAREAN SECTION DELIVERY
}

\section{Neha Rehalia}

\author{
Pediatrician, Civil hospital Shahpur, Kangra (HP).
}

\section{Vivek Chaudhary*}

\author{
Anaesthesiologist, Zonal hospital Dharamshala, Kangra (HP). \\ *Corresponding Author
}

ABSTRACT Background: Globally the rate of caesarean section delivery has been increasing among women. The perceptions surrounding caesarean section delivery may have a significant role in the decision-making process which influenced by multiple complex factors like cultural values, beliefs and anticipations of the birth, possible traumatic events in life, available social support, and personal sense of control, are only a few.

Aim: To compare the attitude towards caesarean section delivery between primigravid women and multigravid women with and without previous history of caesarean section delivery, and also to find the association of attitude of antenatal mothers with their selected demographic variables.

Methodology: The descriptive study approach has been used in view of accomplishing the main objectives of the study. The tools consist of demographic profile along with structured attitude questionnaire. The subject consisted of 10 antenatal mothers and was selected by purposive sampling technique. Data was analyzed by using descriptive and inferential statistics.

Results: The attitude assessed using attitude scale showed that majority of antenatal mothers (60\%) had favorable attitude towards caesarean section. There was no significant relationship between the attitude of primi gravid and multi gravid mothers. There was no significant association found between the attitude of antenatal mothers with their selected demographic variables like age, religion, type of family, education, income per month, residence, and parity.

Conclusion: Although findings revealed that most pregnant women prefer caesarean section delivery, it was found that pregnant women need more guidance by midwives and obstetriciansy.

\section{KEYWORDS : Attitude; Caesarean section delivery; Antenatal mothers}

\section{INTRODUCTION}

Caesarean section, also commonly known as C-section and, is a surgical procedure in which one or more incisions are made through a mother's abdomen and uterus to deliver one or more babies. ${ }^{1}$ A Caesarean section is often performed when a vaginal delivery would put the baby's or mother's life or health at risk. Some are also performed upon request without a medical reason to do so. The WHO recommends that they should be done based only on medical need. ${ }^{2}$

Globally, the rate of caesarean section has been increasing. The safety of the procedure has resulted in some women requesting it in the absence of any medical indication, particularly in the developed countries. ${ }^{3}$ A number of women have good knowledge regarding caesarean section is preferable to vaginal delivery as pain in vaginal delivery is usually unpleasant. Although recent studies have shown that the risk of planned Caesarean Section and planned vaginal delivery in the short term are low and similar, in subsequent pregnancies, the risk will be higher in a mother who has had a previous Caesarean Section. ${ }^{4}$

It is difficult to pinpoint an exact cause for the rising rates of Caesarean sections. Medical, Institutional, legal, psychological and socio-demographic factors play a contributing role. ${ }^{5}$ India is also not excluded from this trend. At the all-India level, the rate has increased from 2.9 per cent of the childbirth in 1992-93 to 7.1 in agreeing for caesarean delivery for medical and even for non medical reason without knowing true risk and benefits of the procedure.

One of the main goals of every medical team, dealing with childbirth, is performing a safe delivery. Caesarean sections are one of the most frequently performed operations in women. One of the most dramatic features of modern obstetrics is the relentless increase in the Caesarean rate. This escalating Caesarean rate is a major public health problem because caesarean section increases the health risk for mothers and babies as well as the cost of health care compared with normal deliveries. ${ }^{7}$ Hence, the study was conducted to compare the attitude towards caesarean section delivery between primigravid women and multigravid women with and without previous history of caesarean section delivery, and also to find the association of attitude of antenatal mothers with their selected demographic variables.

\section{METHODOLOGY}

Ten antenatal mothers, who attended the inpatient and outpatient departments, were enrolled in this study using systematic random sampling at Obstetrics and Gynecology wards and OPD. The antenatal mothers were included if a) antenatal mothers who are available in inpatient/outpatient facility at the setting b) both primi and multi gravid antenatal mothers irrespective of previous history of caesarean section. The mothers were excluded if; $\alpha$ ) mothers in labor process is initiated b) mothers those who are not willing to participate c) mothers who are not available at the time of data collection.

\section{Study Tool}

The study tool consisted of 2 sections. Section I contained 9 items related to demographic profile of the mothers like age, religion, type of family, level of education, occupation, income, residence, and parity. Section II was an attitude scale. The researcher prepared the rating scale consisted of 21 items to assess the attitude of antenatal mothers towards cesarean section. The items were closed ended questions with 5 alternative responses to each. Each item had only one correct response. Correct response carries 5 marks for high level of attitude and 1 mark for low level of attitude. The maximum total score was 105 and minimum total score was 21 .

\section{METHODS}

The investigators visited the obstetric and gynecological ward, OPD and collected data from the participant. After introducing the purpose of the study confidentiality was assured and written consent was obtained from the participants indicating their willingness to participate in the study. The tool was administered to the participants with explanation. After data collection, the investigator thanked the respondents for their participation in the study.

\section{Ethical Consideration}

Ethical clearance was obtained from the Institution Ethics 
Committee. The pilot study was conducted in the obstetric wards.

\section{Data Analysis}

The data were presented as frequency and percentages.

\section{RESULTS}

\section{Demographic Characteristics}

Table 1 shows demographic characteristics of the study subjects. $50 \%$ of the mothers aged between 18 and 25 years followed by $20 \%$ mothers aged 26 to 30 years. Only $10 \%$ mothers aged $>35$ years. $90 \%$ of the study subjects were living in nuclear family and $90 \%$ belonged to rural area. $10 \%$ of them were graduates while only $10 \%$ was illiterate. $70 \%$ of subjects were housewives. Only $10 \%$ mothers have family income of more than Rs. 15000/-. 50\% of the mothers were primigravid women.

Table 1. Demographic Characteristics

\begin{tabular}{|c|c|c|c|}
\hline \multicolumn{2}{|c|}{\begin{tabular}{l|l} 
S.No Variables \\
\end{tabular}} & Frequency (f) & Percentage (\%) \\
\hline 1 & $\begin{array}{l}\text { Age in years } \\
\text { (a) } 18-25 \\
\text { (b) } 26-30 \\
\text { (c) } 31-35 \\
\text { (d) }>36\end{array}$ & $\begin{array}{l}5 \\
2 \\
2 \\
1\end{array}$ & $\begin{array}{l}50 \% \\
20 \% \\
20 \% \\
1 \%\end{array}$ \\
\hline 2 & $\begin{array}{l}\text { Religion } \\
\text { (a) Hindu } \\
\text { (b) Muslim } \\
\text { (c) Christian }\end{array}$ & $\begin{array}{l}10 \\
0 \\
0\end{array}$ & $\begin{array}{l}10 \% \\
0 \\
0\end{array}$ \\
\hline 3 & $\begin{array}{l}\text { Type of family } \\
\text { (a) Nuclear } \\
\text { (b) Joint family }\end{array}$ & $\begin{array}{l}9 \\
1\end{array}$ & $\begin{array}{l}90 \% \\
10 \%\end{array}$ \\
\hline 4 & $\begin{array}{l}\text { Level of education } \\
\text { (a) Illiterate } \\
\text { (b) Primary education } \\
\text { (c) Secondary } \\
\text { education } \\
\text { (d) Graduate } \\
\text { (e) Post graduate } \\
\end{array}$ & $\begin{array}{l}1 \\
7 \\
1 \\
1 \\
1 \\
1\end{array}$ & $\begin{array}{l}10 \% \\
70 \% \\
10 \% \\
\\
10 \% \\
10 \% \\
\end{array}$ \\
\hline 5 & $\begin{array}{l}\text { Occupation } \\
\text { (a) Home maker } \\
\text { (b) Self employed/ } \\
\text { business } \\
\text { (c) Professional } \\
\text { (d) Others }\end{array}$ & $\begin{array}{l}7 \\
1 \\
1 \\
1\end{array}$ & $\begin{array}{l}70 \% \\
10 \% \\
10 \% \\
10 \% \\
\end{array}$ \\
\hline 6 & $\begin{array}{l}\text { Monthly income } \\
\text { (a) }<5000 /- \\
\text { (b) } 5001-10000 /- \\
\text { (c) } 10001-15000 \\
\text { (d) } 15001 \text { and above }\end{array}$ & $\begin{array}{l}5 \\
3 \\
1 \\
1\end{array}$ & $\begin{array}{l}50 \% \\
30 \% \\
10 \% \\
10 \%\end{array}$ \\
\hline 7 & $\begin{array}{l}\text { Residence } \\
\text { (a) Rural } \\
\text { (b) Urban }\end{array}$ & $\begin{array}{l}9 \\
1\end{array}$ & $\begin{array}{l}90 \% \\
10 \% \\
\end{array}$ \\
\hline 8 & $\begin{array}{l}\text { Parity } \\
\text { (a) Primi gravid } \\
\text { (b) Multi gravid }\end{array}$ & $\begin{array}{l}5 \\
5\end{array}$ & $\begin{array}{l}50 \% \\
50 \%\end{array}$ \\
\hline
\end{tabular}

Data Expressed As Frequency And Percentages.

Attitude Of Antenatal Mothers Towards Caesarean Section The data presented in the figure 1 shows that most of the antenatal mothers $(60 \%)$ are had favorable attitude towards caesarean section. Remaining $40 \%$ had unfavorable attitude towards caesarean section.

Comparison of the attitude of primi-gravid women and multigravid women with and without previous history of caesarean section delivery revealed that there was no significant difference between the attitude of women towards caesarian section $(t=0.608)$. Association between the attitude towards caesarian section and selected demographic variables were tried to establish and the results revealed that there were no significant association found between the attitude of antenatal mothers with their selected demographic variables $(p>0.05)$

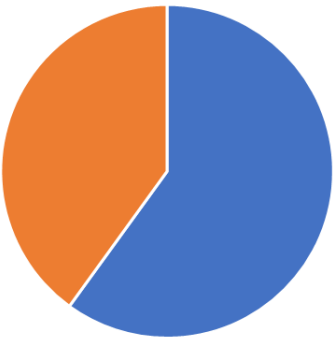

Positive attitude negative attitude

\section{Figure 1: Attitude}

\section{DISCUSSION}

The study findings revealed that most of the antenatal mothers $(60 \%)$ are had favorable attitude towards caesarean section. Remaining $30 \%$ had unfavorable attitude towards caesarean section. A descriptive study was conducted at the University of Benin Teaching Hospital in Nigeria to determine the perceptions and attitudes towards caesarean section. From the study it is found that the women had good knowledge and favorable attitude towards caesarean section; however, only $6.1 \%$ were willing to accept CS as a method of delivery, while $81 \%$ would accept CS if needed to save their lives and that of their babies. Up to $12.1 \%$ of women would not accept CS under any circumstances. Logistic regression showed that women's low level of education, and past successful vaginal and instrumental deliveries, were most likely to be associated with women's non-acceptance of indicated caesarean section. ${ }^{8}$

A cross sectional descriptive study was conducted among Nepalese women with an objective to evaluate the knowledge and attitude towards mode of delivery and caesarean on demand.200 pregnant women after 37 completed weeks of gestation were recruited randomly and interviewed, and their answers were analyzed. Vaginal delivery was the preferred mode in $93 \%$ and $7 \%$ preferred caesarean delivery. Only $35 \%$ of the interviewed women believed that women should have the right to demand a caesarean section. ${ }^{9}$

There were studies which showed different findings from Hong Kong Chinese women aged 18-45, who were pregnant or had given birth within the last three years were recruited. A total of 319 women were recruited, of whom 73 preferred to have a C-section. The results showed that women preferred Csection delivery because they were concerned about being pregnant at an advanced age, were worried about labor pain and perineum tearing, wanted to have a better plan for maternity leave, had chosen an auspicious date to deliver, and perceived that Caesarean section delivery is a more convenience way to deliver. ${ }^{10}$

The present study revealed that there is no difference in the attitude of primi-gravid mothers and multi-gravid mothers towards the caesarian section. However, there was a study conducted at a selected Hospital in Coimbatore. The study was designed to assess knowledge and attitude of antenatal mothers towards caesarean section and normal vaginal delivery. The data was collected from 100 samples by using convenient sampling technique through survey method. Major findings of the study were majority of antenatal mothers had adequate knowledge on mode of delivery. Multi-gravid mothers had positive attitude and primi mothers had negative attitude towards caesarean section. ${ }^{11}$

\section{CONCLUSION}

The main purpose of the study was to assess the attitude of the antenatal mothers towards caesarean section. The rising 
caesarean birth rate in developing countries is an important issue; to decline this trend health professional should provide the true information to the pregnant women and their partners about the modes of delivery, their indications, advantages and adverse consequences during antenatal period. This knowledge will change their outlook and make them a better judge while choosing their preferences.

\section{REFERENCES}

1. Todman D. A history of caesarean section: from ancient world to the modern era. Australian and New Zealand Journal of Obstetrics and Gynaecology. 2007:47:357-61.

2. World Health Organization. Medical device regulations: global overview and guiding principles. World Health Organization; 2003.

3. Betrón $\mathrm{AP}$, Ye J, Moller $\mathrm{AB}$, Zhang J, Gülmezoglu AM, Torloni MR. The increasing trend in caesarean section rates: global, regional and national estimates: 1990-2014. PloS one. 2016 11:e0148343.

4. Keag OE, Norman JE, Stock SJ. Long-term risks and benefits associated with cesarean delivery for mother, baby, and subsequent pregnancies: Systematic review and meta-analysis. PLoS medicine. 2018;15:e1002494.

5. Bayou YT Mashalla YJ, Thupayagale-Tshweneagae G. Patterns of caesarean-section delivery in Addis Ababa, Ethiopia. African journal of primary health care \& family medicine. 2016;8:1-6.

6. Singh P, Hashmi G, Swain PK. High prevalence of cesarean section births in private sector health facilities-analysis of district level household survey-4 (DLHS-4) of India. BMC public health. 2018:18:613.

7. Milcent C, Zbiri S. Prenatal care and socioeconomic status: effect on cesarean delivery. Health economics review. 2018;8:7.

8. Ashimi AO, Amole TG, and Aliyu LD. Knowledge and attitude of pregnant women to caesarean section in a semi urban community in North West Nigeria. JWest Afr Coll Surg 2013;3:46-61.

9. Joshi A, Thapa M, Panta OB. Maternal Attitude and Knowledge towards Modes of Delivery. Journal of Nepal Health Research Council. 2018;16:209-14.

10. Loke AY, Davies L, Li SF. Factors influencing the decision that women make on their mode of delivery: the Health Belief Model. BMC health services research. 2015;15:274

11. Kavitha V. Assessment of Knowledge and Attitude of Antenatal Mothers Towards Caesarean Section and Normal Vaginal Delivery at Selected Hospital, Coimbatore. Asian Journal of Nursing Education and Research. 2013;3:8. 